\title{
MULETA MODULAR: PROCESSO DE GERAÇÃO DA IDEIA
}

Anna Thereza Prates Grillo (annagrillo@hotmail.com) - PPGEP, Escola de Engenharia, Universidade Federal do Rio Grande do Sul

Carla Schwengber ten Caten (carlacaten@gmail.com) - PPGEP, Escola de Engenharia, Universidade Federal do Rio Grande do Sul

Aline Marian Callegaro (nimacall@gmail.com) - PPGEP, Escola de Engenharia, Universidade Federal do Rio Grande do Sul

\section{RESUMO}

$O$ estudo tem como objetivo apresentar uma solução para melhorias em muletas, entendendo e considerando as reais necessidades dos usuários por meio de uma metodologia eficaz de desenvolvimento de produto: o Design Thinking. Com a aplicação de ferramentas propostas por Kumar (2013), que enfatizam a percepção e análise das necessidades dos usuários até a construção de um protótipo, foi possível criar um novo conceito de Muleta Modular, dividida em quatro módulos customizáveis, de acordo com as necessidades de cada usuário. Também foram desenvolvidos acessórios que atendem necessidades práticas. Como forma de validação, o projeto foi apresentado para diferentes usuários de muletas, a uma empresa de produtos ortopédicos e a avaliadores de um programa de empreendedorismo (incluindo universidade e empresa). A Muleta Modular desenvolvida apresenta uma grande contribuição para o conforto físico e emocional das pessoas, podendo reduzir a incidência de lesões causadas pelo uso deste tipo de tecnologia assistiva, resolvendo problemas do cotidiano e, principalmente, colaborando para a redução do estigma social existente em torno da deficiência.

Palavras-chave: desenvolvimento de tecnologia assistiva; design thinking; muleta; muleta modular Área: $O$ design e o desenvolvimento de produtos e serviços

\section{INTRODUÇÃO}

A Tecnologia Assistiva (TA) desempenha um papel importante para a autonomia das pessoas com necessidades especiais (BÜHLER, 1996) e busca cada vez mais adequar dispositivos para que atendem tais necessidades, melhorando assim a qualidade de vida das mesmas (MITTLER, 2007). A TA é importante para a independência de pessoas com limitações físicas e, por isso, é questão-chave identificar e analisar as necessidades dos usuários de muletas, por exemplo, reconhecendo características específicas da vida diária. $\mathrm{O}$ envolvimento do usuário no processo de desenvolvimento é significativo e conhecer as experiências daqueles usuários com longo prazo de uso é fundamental (BÜHLER, 1996).

No caso do mercado atual de muletas do Brasil especificamente, os usuários precisam se adaptar às opções existentes nos formatos disponíveis. A alternativa de modularização é um fator importante na gestão e desenvolvimento de negócios, utilizada como um meio para aumentar a competitividade das organizações (IBRAHIM et al., 2012), demonstrando a preocupação da empresa com a sustentabilidade (SHARMA et al., 2010) e com a percepção do cliente, considerando que a apresentação de diferentes opções de muletas pode aumentar a satisfação do cliente (DU; JIAO; TSENG, 2006). 
Para entender as necessidades dos stakeholders e chegar às melhores soluções do projeto do produto, é possível utilizar a metodologia do Design Thinking (DT), aplicando ferramentas que se baseiam em dados basicamente qualitativos, que possibilitam atender às necessidades diretas dos usuários (KUMAR, 2013). O DT é uma metodologia que está sendo amplamente difundida no mundo dos negócios, com premissas de desenvolvimento de soluções com novas funcionalidades e criando novas experiências, valor e significado para os consumidores (BOER; BONINI, 2015).

O presente estudo tem como tema a Tecnologia Assistiva e sua busca por melhorias na qualidade de vida de pessoas com necessidades físicas especiais. A muleta é um dos equipamentos mais utilizados nos casos de lesões em membros e há uma necessidade de melhoria nas muletas atualmente comercializadas, tendo em vista o grande número de lesões causadas pela falta de conforto das mesmas (MORETZSONH, 2005). Entende-se que a diminuição do estigma social na deficiência deve estar na base do desenvolvimento das TA, atendendo a necessidade latente de satisfação e bem-estar dos usuários (MARTINS, 2009).

Com isso, o objetivo principal da pesquisa é apresentar uma solução de melhoria para muletas, entendendo e considerando as reais necessidades dos usuários por meio de uma metodologia eficaz de desenvolvimento de produto - o Design Thinking.

\section{REFERENCIAL TEÓRICO}

\subsection{Estado da arte das muletas}

Existem quatro tipos de muletas: axilar, de tríceps, de plataforma e de antebraço (modelo canadense). Dentre esses tipos, destacam-se as de modelo canadense e axilar, em termos de oferta no mercado e de preferência pelos usuários (RAMBANI et al., 2007). Por serem modelos que transferem parte do peso do corpo para os membros superiores, o uso prolongado acaba gerando lesões e desconfortos, dentre elas podem ser citadas: degeneração da articulação do ombro, lesões nos braços, mãos e áreas peitorais, síndrome do túnel do carpo e inclusive a possibilidade de neuropatias braquiais compressivas (HUANG et al., 2005; RAMBANI et al., 2007; KEDLAYA; KUANG, 2008).

Quanto à experiência vivida pelo usuário e o padrão de uso, existe uma tendência à descontinuação do uso da muleta, conforme relatado em estudo desenvolvido por Demers et al. (2005). O abandono do uso se dá tanto pelas lesões causadas, quanto pela dificuldade encontrada na realização de atividades cotidianas (CORNMAN et al., 2005; DEMERS et al., 2008; KEDLAYA; KUANG, 2008; WESSELS et al., 2003).

Pesquisa realizada em bancos bibliográficos e de patentes mostrou que existe uma lacuna a ser explorada no desenvolvimento de inovações que atendam às necessidades dos usuários de muletas, tal qual os estudos voltados para a mesma são geralmente em torno das dificuldades enfrentadas, sem abordar resoluções para as problemáticas (GRILLO; SANTOS, 2016).

\subsection{Design Thinking (DT)}

De acordo com Brown (2008), o Design Thinking é uma metodologia criativa para desenvolvimento de inovações que utiliza a sensibilidade e os métodos dos designers para que qualquer pessoa possa resolver problemas e atender às necessidades dos consumidores com uma tecnologia viável e comercialmente factível. O caminho para conseguir a solução ideal passa por desvendar a necessidade dos clientes e elaborar uma estratégia de negócio viável, de modo a ser convertido em valor para o consumidor e, em oportunidade de mercado, para a empresa (BROWN, 2009). 
Para Brown (2008), o processo de Design Thinking gira em torno de três fases fundamentais, onde os problemas são questionados, as ideias geradas e as respostas obtidas. Elas não são lineares, pois podem ocorrer simultaneamente e se repetir para construir as ideias ao longo do percurso da inovação.

- Inspiração: o do problema real que a empresa enfrenta.

- Ideação: geração e a prototipação de ideias e conceitos, ao qual surgem inovações sobre os problemas identificados anteriormente.

- Implementação: planejamento do método que irá atingir a realidade futura esperada.

Com o intuito de obter os melhores resultados em cada fase, é possível utilizar métodos específicos para cada etapa trabalhada, como proposto por Kumar (2013).

\subsection{Métodos de Kumar}

O processo proposto por Kumar (2013) é inovador no design, no qual o mesmo compilou e descreveu ferramentas que visam à inovação. Para isso, ele apresenta sete etapas (Figura 1), onde podem ser aplicados 101 métodos visando a criação de soluções.

Figura 1. Processo inovador no Design. Fonte: Kumar (2013)

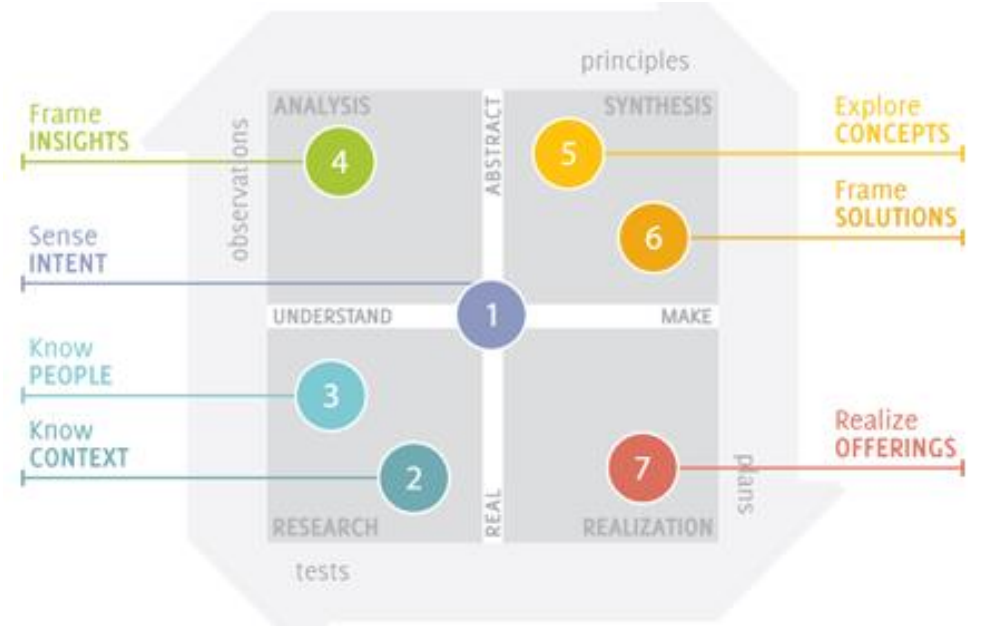

Segundo Kumar (2013), Figura 1, nesse processo há um polo vertical, pelo qual o pensamento flui entre o abstrato e o real, e um polo horizontal, que vai do entendimento à realização. Além disso, ele também está subdividido em quatro quadrantes, que formam um modelo bem estruturado, sendo eles: Pesquisa (Research), Análise (Analysis), Síntese (Synthesis) e Realização (Realization).

As etapas estão inseridas no fluxo do processo, sendo elas:

a) Sense Intent (Declaração da Proposta): descobre-se por onde começar, refletindo sobre a proposta que irá guiar o projeto e as tendências que podem afetá-lo;

b) Know Context (Entendendo o Contexto): estudam-se as circunstâncias ou eventos que afetam o ambiente no qual está inserido a inovação;

c) Know People (Entendendo o Usuário): busca-se entender as pessoas, usuários finais ou partes interessadas, e as suas interações no cotidiano, gerando os insights mais importantes; 
d) Frame Insights (Estruturando Insights): estrutura-se todo o conteúdo encontrado e aprendido nas etapas anteriores, visando encontrar ideias e padrões que serão importantes para o desenvolvimento da inovação;

e) Explore Concepts (Explorando Conceitos): coleta-se ideias para identificar oportunidades e explorar novos conceitos, utilizando dos princípios estruturados anteriormente como ponto de partida;

f) Frame Solutions (Estruturando Soluções): constrói-se o conjunto de conceitos desenvolvidos, transformando as soluções em representações (protótipos).

g) Realize Offerings (Consolidando a Oferta/Produto): avalia-se as soluções e os protótipos testados para fins de iniciar a fase de implementação.

\section{PROCEDIMENTOS METODOLÓGICOS}

Para o desenvolvimento do estudo foram escolhidas ferramentas dentre as propostas por Kumar (2013) sob o critério de priorização das necessidades dos usuários e por serem aplicáveis dentro das condições disponíveis. A escolha do método deu-se pelo mesmo ir de encontro ao proposto pelo Design Thinking, além de permitir a aplicação de um conjunto mais amplo de ferramentas para o desenvolvimento de um produto inovador.

O Quadro 1 apresenta o método de trabalho proposto, com as etapas do desenvolvimento do produto e seus objetivos, as ferramentas aplicadas e a definição de cada uma delas. Como delimitação da pesquisa, as etapas Know Context (Entendendo o Contexto), Frame Solutions (Estruturando Soluções) e Realize Offerings (Consolidando a Oferta/Produto) presentes no processo de Kumar (2013) não serão trabalhadas, tendo em vista que o DT suporta que o processo seja desenhado conforme as necessidades do projeto.

Quadro 1. Método de trabalho - Etapas do desenvolvimento do produto e as ferramentas aplicadas. Fonte: primária.

\begin{tabular}{|c|c|c|c|}
\hline Etapas & Objetivos & $\begin{array}{c}\text { Ferramentas } \\
\text { aplicadas }\end{array}$ & Definição \\
\hline $\begin{array}{l}\text { Imersão Preliminar } \\
\text { (Sense Intent) }\end{array}$ & $\begin{array}{c}\text { Identificar potenciais } \\
\text { oportunidades de inovação para } \\
\text { assim direcionar a pesquisa e a } \\
\text { exploração sobre o tema. }\end{array}$ & $\begin{array}{l}\text { Trends expert } \\
\text { interview }\end{array}$ & $\begin{array}{l}\text { Conversa com especialistas } \\
\text { buscando identificar tendências, } \\
\text { últimos desenvolvimentos e } \\
\text { futuros possíveis. }\end{array}$ \\
\hline $\begin{array}{l}\text { Imersão Profunda } \\
\text { (Know People) }\end{array}$ & $\begin{array}{l}\text { Compreender as atividades, } \\
\text { necessidades e motivações das } \\
\text { pessoas envolvidas visando } \\
\text { suprir tais necessidades e } \\
\text { desenvolver um valor novo e } \\
\text { significativo. }\end{array}$ & $\begin{array}{l}\text { POEMS } \\
\text { (People; } \\
\text { Object; } \\
\text { Environment; } \\
\text { Message; } \\
\text { Service) } \\
\end{array}$ & $\begin{array}{l}\text { Estudo das pessoas (P-people), } \\
\text { objetos }(O \text {-objects }), \text { ambientes } \\
\text { (E-environments), mensagens } \\
\text { (M-messages }), \text { e serviços }(S- \\
\text { services }) \text { num contexto. }\end{array}$ \\
\hline $\begin{array}{l}\text { Análise e Síntese } \\
\text { (Frame Insights) }\end{array}$ & $\begin{array}{l}\text { Identificar novas oportunidades } \\
\text { de inovação a partir do know } \\
\text { people e know context. }\end{array}$ & $\begin{array}{c}\text { User response } \\
\text { analysis }\end{array}$ & $\begin{array}{c}\text { Análise das respostas dos } \\
\text { participantes da pesquisa } \\
\text { buscando entender os padrões e } \\
\text { gerar insights. }\end{array}$ \\
\hline \multirow{2}{*}{$\begin{array}{c}\text { Ideação (Explore } \\
\text { Concepts) }\end{array}$} & \multirow{2}{*}{$\begin{array}{l}\text { Explorar ideias relevantes, } \\
\text { gerar conceitos e criar valores } \\
\text { centrados nas pessoas e no } \\
\text { contexto. }\end{array}$} & $\begin{array}{c}\text { Ideation } \\
\text { Session } \\
\text { (Brainstorming } \\
\text { ) }\end{array}$ & $\begin{array}{l}\text { Sessão para geração de ideias } \\
\text { com base no conhecimento } \\
\text { adquirido sobre as pessoas e o } \\
\text { contexto. }\end{array}$ \\
\hline & & $\begin{array}{l}\text { Summary } \\
\text { Framework }\end{array}$ & $\begin{array}{l}\text { Criação de um quadro resumindo } \\
\text { os insights chave para análise. } \\
\text { Contém informações abrangentes } \\
\text { para a discussão. }\end{array}$ \\
\hline
\end{tabular}




\section{RESULTADOS}

\subsection{Imersão Preliminar}

Na etapa de Imersão Preliminar foi utilizada a ferramenta Trends expert interview, que se trata de entrevistar envolvidos a fim de compreender as necessidades e identificar tendências e futuros possíveis. A ferramenta foi aplicada conforme os passos descritos a seguir:

a) Determinação dos tópicos para entendimento: buscou-se perceber a rotina do entrevistado, as dificuldades que o mesmo enfrenta ou enxerga e os sentimentos associados a cada ponto levantado.

b) Identificação dos especialistas entrevistados: foram entrevistados usuários de muletas permanentes e temporários, familiares, profissionais da saúde (médico ortopedista e fisioterapeuta) e profissionais do comércio de produtos ortopédicos.

c) Preparações para a entrevista: optou-se por realizar conversas informais, com alguns tópicos norteadores - como rotina, dificuldades, problemas e percepções - com fins de obter o retorno mais honesto possível e evitando a indução de respostas.

d) Condução das entrevistas: as entrevistas foram realizadas pessoalmente ou por vídeochamada, sendo todas gravadas e posteriormente transcritas.

e) Análise e síntese: após a transcrição dos aúdios, o grupo se reuniu para elencar as principais percepções obtidas, apresentadas na continuidade da presente seção.

Verificou-se uma distinção na percepção dos usuários permanentes e temporários, os primeiros possuem uma motivação emocional envolvida, pois entendem que é um problema que possuem e precisam lidar pelo resto da vida. Dessa forma, identificou-se a importância de considerar o conforto emocional que a inovação pode trazer. Também foi possível compreender dificuldades em pequenas atividades do cotidiano, como no carregamento de objetos, ato de subir escadas, utilização de transportes públicos, apoio das muletas quando não estão em uso e prática de exercícios e brincadeiras, principalmente no que diz respeito às crianças, locomoção em terrenos desnivelados, entre outros. Em relação ao conforto, a maior reclamação é para o pegador no punho, pois além de causar calosidades nas mãos, estas também escorregam em dias quentes ou em pessoas que possuem sudorese (suor excessivo).

Os profissionais da área da saúde apontam que as muletas axilares e canadenses são os produtos assistivos que mais atendem a sociedade. Os usuários temporários são uma grande parcela, bem como pacientes neurológicos e amputados. Eles atentam para o grande número de lesões causadas pela falta de ergonomia e conforto, sendo recorrente o tratamento dessas, o que torna a vivência com as muletas ainda mais difícil.

O ponto de vista dos vendedores de produtos ortopédicos está voltado para o mercado. Segundo os mesmos, os usuários permanentes investem mais nas muletas, porém não encontram muitas opções que se adequem às suas necessidades específicas. A maior clientela fica por parte dos usuários temporários, que não estão dispostos a dispor de um grande investimento, buscando muitas vezes empréstimos ou os serviços de aluguéis.

O problema da falta de adaptabilidade das muletas para as diferentes estruturas corporais e necessidades específicas se mostra latente para todos os entrevistados.

\subsection{Imersão Profunda}

Na etapa de imersão profunda foi utilizada a ferramenta POEMS para compreender melhor o contexto e as necessidades dos usuários de muletas, bem como o meio no qual estão inseridos. Para tanto, realizaram-se três fases: 
a) Preparação para saída de campo: preparou-se questionamentos sobre a rotina, atividades cotidianas, dificuldades e sentimentos associados.

b) Saída de campo: foram feitas três saídas de campo, sendo uma para observar e conversar com usuários e familiares; outra para consultar os profissionais da saúde mais envolvidos: um médico ortopedista e um fisioterapeuta; e a última saída contemplou visitas em lojas de produtos ortopédicos para compreender o serviço.

c) Entendimento e análise pelo POEMS: após transcrição dos áudios das entrevistas e uma análise e compreensão de cada elemento, preencheu-se o POEMS com as percepções obtidas, conforme é apresentado no Quadro 2.

Quadro 2. Desenvolvimento da ferramenta POEMS. Fonte: primária.

\begin{tabular}{|c|c|c|c|}
\hline & & Entendendo o contexto & Percepções obtidas em campo \\
\hline Pessoas & $\mathrm{P}$ & $\begin{array}{l}\text { As principais pessoas envolvidas } \\
\text { na utilização de muletas são } \\
\text { portadores de necessidades físicas } \\
\text { especiais (usuários permanentes) } \\
\text { ou pessoas que sofreram algum } \\
\text { tipo de trauma (usuários } \\
\text { temporários). }\end{array}$ & $\begin{array}{c}\text { Usuários temporários percebem a utilização de } \\
\text { muletas como uma experiência nova que permite } \\
\text { entender os usuários permanentes. Percebe-se que } \\
\text { as mãos estão sempre ocupadas. Usuários } \\
\text { permanentes possuem uma questão emocional } \\
\text { envolvida muito forte acerca do estigma social } \\
\text { existente. }\end{array}$ \\
\hline Objetos & $\mathrm{O}$ & $\begin{array}{l}\text { Os objetos utilizados no uso da } \\
\text { muleta são: muleta (obrigatório), } \\
\text { luvas para proteção das mãos, } \\
\text { sacola para carregar os pertences } \\
\text { ou mochila (opcional). }\end{array}$ & $\begin{array}{l}\text { São utilizadas muletas canadense, axilar ou } \\
\text { andadores. O objeto escolhido varia conforme a } \\
\text { adaptação dos usuários, pois há um padrão já } \\
\text { estabelecido. Luvas são usadas mais por usuários } \\
\text { permanentes, mas se percebe um incômodo com } \\
\text { o uso das mesmas. }\end{array}$ \\
\hline Ambientes & $\mathrm{E}$ & $\begin{array}{l}\text { O ambiente onde os usuários de } \\
\text { muletas estão inseridos é qualquer } \\
\text { ambiente de circulação e vivência, } \\
\text { seja a rua, prédios, casa, } \\
\text { shoppings, etc. }\end{array}$ & $\begin{array}{l}\text { Os usuários percebem dificuldades nas tarefas } \\
\text { domésticas, subir escadas e para abrir portas. } \\
\text { Dificuldade de locomoção nas ruas à noite, por } \\
\text { segurança e também em pisos desformes. }\end{array}$ \\
\hline Mensagens & M & $\begin{array}{l}\text { Pessoas que utilizam muletas } \\
\text { pertencem ao grupo com } \\
\text { dificuldades de acessibilidade. }\end{array}$ & $\begin{array}{c}\text { Usuário percebe que quando as muletas não estão } \\
\text { consigo, é como se faltasse uma parte do seu } \\
\text { corpo. Pessoas que usam muletas são vistas como } \\
\text { "deficientes". }\end{array}$ \\
\hline Serviços & $\mathrm{S}$ & $\begin{array}{l}\text { As muletas podem ser compradas, } \\
\text { alugadas ou emprestadas. }\end{array}$ & $\begin{array}{c}\text { Há quebras na parte do apoio e perda da borracha } \\
\text { de segurança. As muletas são facilmente } \\
\text { encontradas no mercado em lojas de produtos } \\
\text { ortopédicos, porém sem muitas opções de } \\
\text { modelos e marcas. }\end{array}$ \\
\hline
\end{tabular}

\subsection{Análise e Síntese}

Todas as informações coletadas nas etapas anteriores foram reunidas, analisadas e transformadas em ideias. Foi utilizada a ferramenta User Response Analysis para analisar as respostas dos participantes entrevistados anteriormente, tornando assim possível entender os padrões e gerar os insights. A Quadro 3 mostra a compilação dos pontos identificados.

Quadro 3. Desenvolvimento do método User Response Analysis. Fonte: primária.

\begin{tabular}{|c|c|c|c|c|c|c|c|}
\hline Item & Segurança & Estética & $\begin{array}{c}\text { Fator de } \\
\text { compra }\end{array}$ & $\begin{array}{c}\text { Aspectos } \\
\text { negativos }\end{array}$ & Preço & Qualidade & Social \\
\hline $\begin{array}{c}\text { Respostas }- \\
\text { Usuários } \\
\text { permanentes e } \\
\text { temporários }\end{array}$ & $\begin{array}{c}\text { Em dias de } \\
\text { chuva há } \\
\text { maior risco de } \\
\text { quedas. }\end{array}$ & $\begin{array}{c}\text { Para } \\
\text { crianças e } \\
\text { jovens } \\
\text { percebe-se }\end{array}$ & $\begin{array}{c}\text { Por } \\
\text { adaptação do } \\
\text { usuário. }\end{array}$ & $\begin{array}{c}\text { Dificuldade } \\
\text { de adaptação } \\
\text { com a } \\
\text { muleta e }\end{array}$ & $\begin{array}{c}\text { Usuários } \\
\text { permanent } \\
\text { es estão } \\
\text { dispostos a }\end{array}$ & $\begin{array}{c}\text { Há valor } \\
\text { agregado } \\
\text { percebido } \\
\text { pela }\end{array}$ & $\begin{array}{c}\text { Há } \\
\text { dificuldades } \\
\text { de } \\
\text { acessibilidad }\end{array}$ \\
\hline
\end{tabular}




\begin{tabular}{|c|c|c|c|c|c|c|c|}
\hline & & $\begin{array}{c}\text { uma } \\
\text { preocupaçã } \\
\text { o maior } \\
\text { com a } \\
\text { estética. }\end{array}$ & & $\begin{array}{c}\text { execução de } \\
\text { tarefas } \\
\text { cotidianas. } \\
\text { Ocorrência } \\
\text { de lesões } \\
\text { com o uso. }\end{array}$ & $\begin{array}{c}\text { investir } \\
\text { mais em } \\
\text { qualidade. }\end{array}$ & $\begin{array}{c}\text { durabilidade } \\
\text { da muleta e } \\
\text { adaptabilida } \\
\text { de do } \\
\text { usuário. }\end{array}$ & $\begin{array}{c}\text { e e estigma } \\
\text { social em } \\
\text { torno da } \\
\text { deficiência. }\end{array}$ \\
\hline $\begin{array}{c}\text { Respostas - } \\
\text { Profissionais } \\
\text { da saúde }\end{array}$ & $\begin{array}{l}\text { Muletas } \\
\text { canadenses } \\
\text { articuladas } \\
\text { auxiliam a } \\
\text { segurar um } \\
\text { copo. }\end{array}$ & $\begin{array}{c}\text { Não foi } \\
\text { mencionad } \\
\text { o. }\end{array}$ & $\begin{array}{c}\text { Cores são } \\
\text { mais } \\
\text { atrativas. } \\
\text { Maior } \\
\text { conforto. }\end{array}$ & $\begin{array}{l}\text { Lesões no } \\
\text { punho e } \\
\text { nervos } \\
\text { axilar. }\end{array}$ & $\begin{array}{c}\text { Sistema } \\
\text { Único de } \\
\text { Saúde } \\
\text { (SUS) tem } \\
\text { tabela de } \\
\text { valores, se } \\
\text { a muleta } \\
\text { não se } \\
\text { enquadrar } \\
\text { não } \\
\text { atingirá } \\
\text { grande } \\
\text { parte da } \\
\text { população. }\end{array}$ & $\begin{array}{c}\text { Deve existir } \\
\text { uma } \\
\text { funcionalida } \\
\text { de para se } \\
\text { adaptar aos } \\
\text { diferentes } \\
\text { contextos, } \\
\text { visando uma } \\
\text { maior } \\
\text { qualidade de } \\
\text { vida. }\end{array}$ & $\begin{array}{c}\text { As muletas } \\
\text { fazem parte } \\
\text { das } \\
\text { tecnologias } \\
\text { assistivas. } \\
\text { Resistência } \\
\text { no uso. }\end{array}$ \\
\hline $\begin{array}{l}\text { Respostas - } \\
\text { Vendedor de } \\
\text { produtos } \\
\text { ortopédicos }\end{array}$ & $\begin{array}{c}\text { Não foi } \\
\text { mencionado. }\end{array}$ & $\begin{array}{c}\text { Crianças e } \\
\text { jovens } \\
\text { solicitam } \\
\text { opções de } \\
\text { cores, mas } \\
\text { não } \\
\text { existem } \\
\text { muitas. }\end{array}$ & $\begin{array}{c}\text { Pela pouca } \\
\text { diferença } \\
\text { existente } \\
\text { entre as } \\
\text { muletas } \\
\text { oferecidas, } \\
\text { as pessoas } \\
\text { optam pelas } \\
\text { mais baratas. }\end{array}$ & $\begin{array}{c}\text { Poucas } \\
\text { opções no } \\
\text { mercado. } \\
\text { Dificuldade } \\
\text { de } \\
\text { locomoção } \\
\text { dos usuários. }\end{array}$ & $\begin{array}{c}\text { Diferença } \\
\text { de preço é } \\
\text { pequena } \\
\text { entre as } \\
\text { mais } \\
\text { comuns. }\end{array}$ & $\begin{array}{l}\text { Diferença de } \\
\text { qualidade } \\
\text { em } \\
\text { materiais, } \\
\text { como o da } \\
\text { base de } \\
\text { borracha } \\
\text { que ocorre } \\
\text { desgaste. }\end{array}$ & $\begin{array}{c}\text { Não foi } \\
\text { mencionado. }\end{array}$ \\
\hline
\end{tabular}

Aponta-se como principais padrões a serem considerados: (i) a falta de diversidade de produtos disponíveis no mercado; (ii) o grande número de lesões e desconforto; (iii) a dificuldade de mobilidade e de execução de tarefas cotidianas por parte dos usuários; (iv) o estigma social em torno da deficiência; e (v) a falta de adaptabilidade das muletas para os diferentes tipos de estruturas corporais.

\subsection{Ideação}

$\mathrm{Na}$ etapa de Ideação foi utilizada a ferramenta Ideation Session (Brainstorming). As ideias foram propostas pela equipe de maneira aleatória, com cada integrante apontando os insights que tiveram ao longo das experiências. Com a listagem das ideias realizada, analisou-se uma a uma, descartando as inviáveis, sob critérios factibilidade e coerência com o escopo do projeto, e selecionando assim as melhores propostas. As melhores ideias foram analisadas e classificadas de acordo com fatores como: viabilidade econômico-financeira e de produção, interesse do cliente, atendimento às necessidades do usuário (satisfação) e nível de inovação. Desta forma foi selecionada a ideia que resultou no projeto a ser desenvolvido pela equipe: uma muleta modular e customizável.

Após definida a ideia principal do projeto, realizou-se um novo brainstorming, desta vez para levantar novas ideias e insights específicos para as características do produto, passando para a próxima ferramenta de análise deste levantamento e de determinação das características: o Summary Framework. O Quadro 4 apresenta as ideias levantadas durante o brainstorming realizado, agrupadas segundo o seu foco e selecionadas após a discussão e a análise, levando em conta os mesmos fatores considerados anteriormente: viabilidade econômico-financeira e de produção, interesse do cliente, atendimento às necessidades do usuário (satisfação) e nível de inovação. Estas ideias compõe a nova proposta de muleta a ser apresentada. 
Quadro 4. Desenvolvimento do método Summary Framework. Fonte: primária.

\begin{tabular}{|c|c|c|c|}
\hline Produto & Módulos & Mercado & Acessórios \\
\hline $\begin{array}{c}\text { Uma muleta com quatro módulos: } \\
\text { Braçadeira, Empunhadura, Haste e } \\
\text { Base }\end{array}$ & $\begin{array}{l}\text { Módulo Haste em } \\
\text { bambu }\end{array}$ & $\begin{array}{l}\text { Desenvolvimento } \\
\text { de acessórios que } \\
\text { atendam às } \\
\text { necessidades } \\
\end{array}$ & $\begin{array}{l}\text { Capa acolchoada } \\
\text { para a } \\
\text { Empunhadura }\end{array}$ \\
\hline $\begin{array}{c}\text { Substituir a peça reflexiva na } \\
\text { Empunhadura por adesivo refletor (a } \\
\text { peça cai com frequência) }\end{array}$ & $\begin{array}{c}\text { Módulos } \\
\text { Empunhadura e } \\
\text { Base em diferentes } \\
\text { formatos } \\
\end{array}$ & $\begin{array}{l}\text { Vender módulos e } \\
\text { acessórios em } \\
\text { farmácias }\end{array}$ & $\begin{array}{l}\text { Bolsa especial para } \\
\text { acoplar na Haste }\end{array}$ \\
\hline $\begin{array}{l}\text { Encaixes fáceis de manipular entre } \\
\text { os módulos }\end{array}$ & $\begin{array}{c}\text { Módulo Braçadeira } \\
\text { em diferentes cores } \\
\text { e estampas } \\
\text { (principalmente as } \\
\text { infantis) } \\
\end{array}$ & $\begin{array}{l}\text { Apresentação em } \\
\text { módulos no } \\
\text { mercado, o cliente } \\
\text { monta na hora da } \\
\text { compra } \\
\end{array}$ & $\begin{array}{l}\text { Fita reflexiva para } \\
\text { a Haste e para a } \\
\text { Empunhadura }\end{array}$ \\
\hline- & $\begin{array}{l}\text { Uso de materiais } \\
\text { alternativos e } \\
\text { ecológicos em } \\
\text { todos os módulos }\end{array}$ & (2) & - \\
\hline
\end{tabular}

Tendo em vista todos os pontos listados, definiu-se que a Muleta Modular deve possuir quatro módulos: (1) braçadeira, (2) empunhadura, (3) haste e (4) base, conforme apresentado na Figura 2. Cada módulo pode ser oferecido com múltiplas opções, que variam em fatores como: cor, design, formato, tamanho, material e ergonomia. Além disso, definiu-se também o desenvolvimento de alguns acessórios com o objetivo de atenderem necessidades específicas de um novo segmento/nicho de mercado. Os acessórios a serem desenvolvidos são: capa acolchoada para a empunhadura, bolsa especial acoplável e fitas reflexivas.

Figura 2. Muleta Modular: a) vista isométrica; b) vista explodida - 1 - módulo braçadeira, 2 empunhadura, 3 - módulo haste e 4 - módulo base. Fonte: primária.

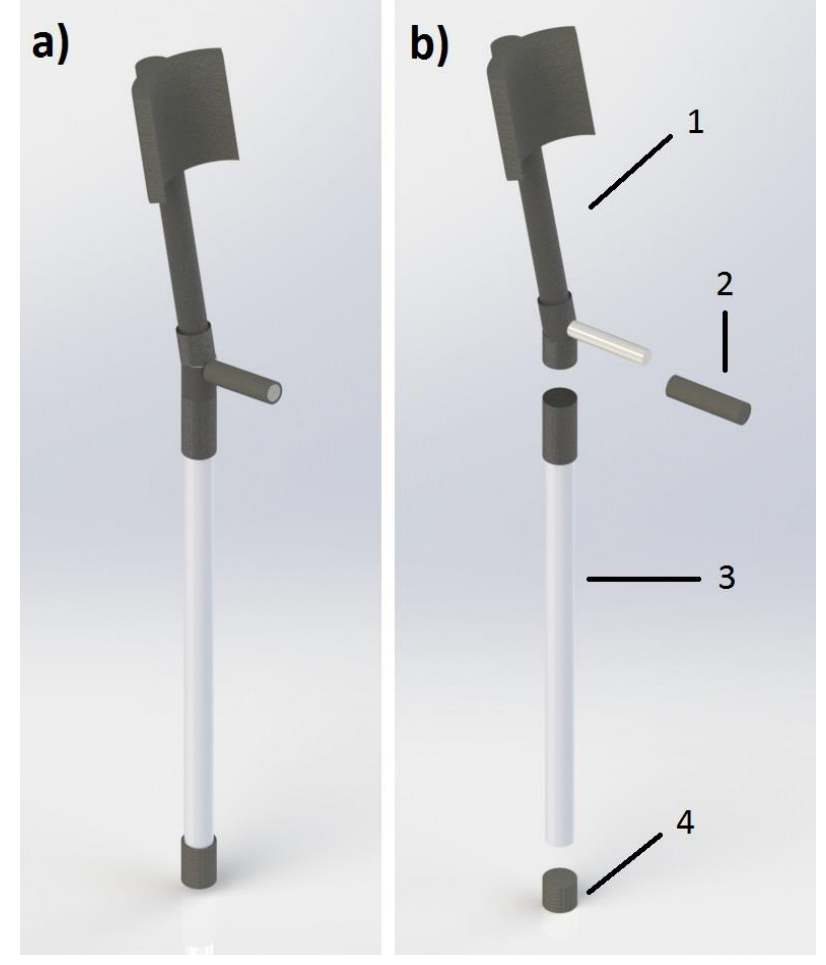




\section{CONSIDERAÇÕES FINAIS}

O objetivo principal deste estudo visou apresentar uma proposta de melhorias em muletas, levando em consideração as reais necessidades do usuário. Ao utilizar como base a metodologia do Design Thinking e os métodos propostos por Kumar (2013), chegou-se na solução de uma Muleta Modular, atendendo com satisfação o objetivo proposto.

Ao longo das aplicações das ferramentas selecionadas no método de trabalho, verificou-se a falta de adaptabilidade das opções de muletas existentes no mercado, o que resulta em dificuldades na continuidade do uso, lesões e sentimento de desconforto. Para isso, a modularização da muleta permite que os módulos sejam trabalhados unitariamente e muletas customizadas possam ser oferecidas para os clientes, atendendo as necessidades individuais dos usuários e melhorando assim a satisfação dos mesmos com o produto.

Outro diferencial do produto apresentado neste estudo está na possibilidade da organização ter soluções viáveis e vendáveis, com possível redução do custo de fabricação e, consequentemente, de variação do valor do produto. Uma vez que não foram alterados os fundamentos do produto, o projeto se torna executável considerando que as empresas fabricantes não precisariam fazer grandes modificações no seu processo produtivo e maquinário atual. Também se pode explorar a vendabilidade do produto, criar novos acessórios e novos nichos de mercado. Além de aumentar o mix de produtos, é possível explorar novos pontos de vendas, como, por exemplo, farmácias, que já comercializam contenções elásticas e outros produtos ortopédicos de menor porte.

Como forma de validação da ideia, o projeto foi apresentado para diferentes usuários de muletas e a uma grande empresa fabricante de produtos ortopédicos situada no sul do Brasil, ao qual receberam a proposta com surpresa e satisfação, principalmente em relação às soluções advindas dos acessórios desenvolvidos que resolvem problemas da vida cotidiana. $\mathrm{O}$ projeto também foi apresentado em um programa realizado pela Escola de Engenharia da UFRGS em conjunto com uma empresa voltada para o empreendedorismo, recebendo a segunda colocação por possuir uma alta capacidade de impacto social e de viabilidade de execução.

Sugere-se como continuidade da pesquisa o desenvolvimento da etapa Frame Solutions (Estruturando Soluções) proposta por Kumar (2013), onde deverão ser realizados os protótipos para identificação e implementação de pontos a melhorar no projeto.

\section{REFERÊNCIAS}

BOER, G.; BONINI, L. Design thinking: uma nova abordagem para inovação. Disponível em Terra Forum Consultores: http://biblioteca.terraforum.com.br> Acesso em 14 de junho de 2015.

BROWN, T. Design Thinking. Harvard Business Review, June, 2008.

BROWN, T. Change by design: how design thinking transforms organizations and inspires innovation. New York: HarperCollins, 2009.

BÜHLER, C. Approach to the analysis of user requirements in assistive technology. International Journal of Industrial Ergonomics, v17, n. 2, p. 187-192, 1996.

CORNMAN, J. C.; FREEDMAN, V. A.; AGREE, E. M. Measurement of assistive device use: implications for estimates of device use and disability in late life. The Gerontologist, v45, n. 3, p. 347-358, 2005. 
DEMERS, L.; FUHRER, M. J.; JUTAI, J. W.; SCHERER, M.; PERVIEUX, I.; DERUYTER, F. Tracking mobilityrelated assistive technology in an outcomes study. Assistive Technology, v20, p. 73-83, 2008.

DU, X.; JIAO, J.; TSENG, M. M. Understanding customer satisfaction in product customization. The International Journal of Advanced Manufacturing Technology, v31, n. 34, p. 396-406, 2006.

GRILlO, A.; SANTOS, G. Muleta Modular: Revisão bibliográfica e de patentes. 2016. Dissertação (Mestrado em Engenharia de Produção)- Universidade Federal do Rio Grande do Sul, Porto Alegre, Brasil, 2016.

HUANG, K.; HSU, W.; LEE, K.; HSU, R. W. Did the use of crutches in an elderly patient activate a dormant subclavian lymphatic malformation? A case report. Acta Orthopaedica, v76, n. 5, p. 725-727, 2005.

IBRAHIM, A.; SABARI, R.; AMLUS, M. H.; ARIFFIN, A. S.; NAIMAH, A.; MOKHTAR, S. Factors that contribute in successful implementing of modularity product: study of manufacturing firm in malaysia. Proceedings of the Knowledge Management International Conference (KMICe), 2012. Johor Bahru, Malaysia.

KEDLAYA, D.; KUANG, T. Assistive devices to improve independence. 2008. Disponível em: <http://emedicine.medscape.com/article/325247-overview>. Acesso em: 27/11/2016.

KUMAR, V. 101 Design Methods: a structured approach for driving innovation in your organization. New Jersey: John Wiley \& Sons, 2013.

MARTINS, J. A. Aspectos da experiência da deficiência física: uma abordagem sócioantropológica. 2009. Dissertação (Mestrado em Saúde Coletiva)- Universidade Federal de Mato Grosso, Cuiabá, Brasil, 2009.

MITTLER, J. Assistive Technology and IDEA: Regulations. Technology Integration: Providing Access to the Curriculum for Students with Disabilities, Long Island University, p. 81-85, 2007.

MORETSZONH, O. Os auxiliadores da marcha. Uso de muletas, bengalas e andadores. Campinas, 2005.

RAMBANI, R.; SHAHID, M. S.; GOYAL, S. The use of a hands-free crutch in patients with musculoskeletal injuries: randomized control trial. International Journal of Rehabilitation Research, v30, n. 4, p. 357-359, 2007.

SHARMA, A.; IYER, G. R.; MEHROTRA, A.; KRISHNAN, R. Sustainability and businessto-business marketing: a framework and implications. Industrial Marketing Management, v39, n. 2, p. $330-341,2010$.

WESSELS, R.; DIJCKS, B.; SOEDE, M. Non-use of provided assistive technology devices: a literature overview. Technology and Disability, v15, n. 4, p. 231-238, 2003. 